\title{
Household Latrines to Control Environmental Contamination and Helminthiasis: An Exploratory Study in Indonesia
}

\author{
M. J. Park, Budi Laksono, Ross Sadler, Archie Clements, and Donald E. Stewart
}

\begin{abstract}
In rural Indonesia, soil-transmitted helminth (STH) infections cause health problems and impair social development. We investigated whether those problems could be solved by the use of household latrines (the 'BALatrine'). Our method was to study two villages, of which only one had household latrines. The dependent variables were environmental contamination (Escherichia coli in well water), STH-related illnesses and symptoms, and absence from work or school due to bowel infections. The village with latrines had less $E$. coli contamination. STH-related illnesses and symptoms were less prevalent among participants who had a latrine than among those who did not. Absence from work or school due to bowel infection was much less common among participants who had a latrine than among those who did not $(6.2 \%$ vs $40.3 \%)$. In conclusion, the BALatrine could have important public-health and social benefits, and that hypothesis should be tested in a controlled longitudinal study.
\end{abstract}

Index Terms-BALatrine, bowel infections, hygiene, Indonesia, parasites, sanitation.

\section{INTRODUCTION}

Sanitation in Indonesia varies widely between rich and poor and between rural and urban populations. In 2010, nationally, three out of 10 households still had no family latrine [1]. National baseline data from 2007 indicate that about the same proportion (29\%) have inappropriate behaviour relating to defecation and less than a quarter (23.2\%) have appropriate behaviour relating to hand-washing [2]. Only $35 \%$ of the rural Indonesian population has access to improved latrines, that is, facilities that hygienically separate human excreta from human contact [3]. Open defecation has been noted in $55 \%$ of the poorest households and in $18 \%$ of the richest [4]. In these circumstances, it appears unlikely that Indonesia will reach the Millennium Development target level of $75 \%$ sanitation coverage by 2015 [5].

Open defecation leads to the contamination of the environment with gastrointestinal bacteria, viruses, and parasites, with waterways and rivers disseminating them

Manuscript received December 13, 2013; revised February 14, 2014. This work was supported in part by the UBS Optimus Foundation.

M. J. Park, Donald E. Stewart, and Ross Sadler are with the School of Public Health at Griffith University, Brisbane, Australia (e-mail: mj.park@griffith.edu.au, donald.stewart@griffith.edu.au).

Budi Laksono is with the Semarang, Central Java, Indonesia (e-mail: blaksono@yahoo.com).

Archie Clements is with the School of Population Health of the University of Queensland, Brisbane, Australia (e-mail: a.clements@uq.edu.au). across inhabited areas [6]. Most of the waterways in the rural regions of Central Java are used for sanitary purposes and many wells are contaminated [7]. Gastrointestinal infections are a major problem in Indonesia, causing 165,000 deaths in 2005 [8]. The Health Department reported that the rate of cases increased from 2000-2009, with a small decrease in 2010 [9]. Diarrhoea is the number one cause of infant mortality (31.4\%) and is also the major cause of mortality for children under 5 years old $(25.2 \%)$ [9]. In Central Java province, 420,587 people received medication from public health centres due to diarrhoea and 7,648 were reported hospitalized. Just under half $(45 \%)$ of those affected were children under 5 years old [10]. Laksono [11] found that $84-92 \%$ of children in elementary school were infected by intestinal worms. Health Department research in 40 elementary schools in 10 provinces indicated that worm infestation affects up to $96 \%$ of students [10]. Hendratno also found high levels of pinworm infection $(67.9 \%$ of students in Kandang Serang; $74.3 \%$ of students in Lambur Pekalongan) [12]. Anggoro noted that $56.9 \%$ of school children in Jakarta were infected with pinworm [13]. In Central Java Province, the prevalence of soil-transmitted helminth (STH) infections is high (Ascaris lumbricoides 45.6\%, Ancylostoma duodenale $12.7 \%$, and Trichuris trichiura $31.5 \%$ ) and the prevalence of mixed infections is $59.2 \%$ [14]. In the same province, examination of over 2000 soil samples from 13 sites indicated a $45 \%$ positive worm egg contamination rate [14].

Use of latrines could solve many of the problems caused by open defecation, both in regular daily life and also in emergency situations [15]. However, campaigns to promote the use of latrines in developing countries often fail, particularly when the technology used is not appropriate to the local environment and to the available human resources. Budi's Amphibious Latrine (the 'BALatrine') [16] is a household latrine designed to be made by local people using local materials in developing-country villages. It is compatible with the users' habits, funds, and environment. The BALatrine has two configurations: one for use if there is enough water for flushing, and one for use if such water is not available. It is inexpensive and can be copied by people with very limited income or by governments or private organizations. Details of the BALatrine and its construction have been published elsewhere [17].

The BALatrine has been in use as a regular household latrine in Central Java for over 15 years [16] but a scientific analysis is lacking regarding its impact. As a first step, we have investigated, using quantitative methods, if there are health and environmental-contamination differences between a village that has introduced household latrines and a village 
that has not. This was a cross-sectional study designed to identify associations and differences between villages with or without household latrines, along the dimensions of villagers' hygiene, environmental quality, individual-level health, and the social impact of STH infection.

\section{METHODS}

\section{A. Setting}

This study focused on two villages close to Semarang, Central Java, Indonesia, in the Gunungpati sub-district, which is a wooded, semi-urban area south of Semarang characterized by high hills. Both villages are in the same sub-district, but they are not close to each other. One of the villages had household BALatrines, and the other did not.

\section{B. Design and Construction of the BALatrine}

Much of the technology and many of the materials needed for the BALatrine are already available in villages in Central Java, such as mattock, crowbar, handsaw, trowel, small pieces of timber or bamboo, cement, sand, split stone, and pieces of PVC pipe.

Like many other squat latrines, the BALatrine is simple [17]. It comprises a septic tank or pit, a concrete plate or mold and a removable U-bend water closet-barrier. With the dry option, a lid is required to minimise access by insects and the escape of odours. The dry option is not ideal, but is an improvement on pollution of waterways. For the 'wet' option, a water closet (U-bend barrier) is added, which makes this latrine similar to others that have been found to be effective against the spread of STH infections [18]-[20]. A water reservoir is not recommended, as the still water would allow mosquitoes to breed.

\section{Variables and Measurements}

The independent variable was the household BALatrine (i.e., its presence or absence). There were three types of dependent variables: environmental, individual-health, and social. The environmental outcome was contamination of well water. The individual-health outcomes were five STH-related symptoms and illnesses. The social outcome was absence from work or school due to bowel infections.

Samples of water were taken from wells in the villages, and were tested for Escherichia coli.

A questionnaire (the "Helminth Education and Latrine Project" (HELP) questionnaire) was used to collect information regarding all village residents who were 3 to 70 years old. In addition to basic socio-demographic questions, the questionnaire collected data about housing conditions, knowledge of parasites and bowel infections, hygiene behaviors, STH-related symptoms and illnesses within the past three months, and the number of days absent from school or work due to bowel infection within the past three months. Survey researchers also examined each participant's hands and fingernails, and recorded their cleanliness.

\section{Data Analysis}

Differences between the participants with and those without household latrines were tested with Fisher's exact test, the Mann-Whitney U test, and Pearson's Chi-square test, as specified in the Tables. Data were analysed with IBM SPSS Version 20.0, Microsoft Excel, and the "Open Source
Epidemiologic Statistics for Public Health" at <www.openepi.com>.

\section{E. Ethics}

Before the study commenced, ethical approval was obtained from the Semarang City authorities (ref. 070/613/IV/2011), and from the Human Research Ethics Committees at Diponegoro University and at Griffith University (ref. PBH/17/11/HREC).

\section{RESUlTS}

\section{A. Background (Table I)}

Biological, socio-demographic, and housing-related details are shown in Table I. The total number of participants was 804, of whom approximately half had a household latrine. With regard to age and sex there were no important differences between those who had a latrine and those who did not have a latrine. Also, in both of those groups almost $90 \%$ of the participants had completed at least elementary school. Regarding employment and income there were statistically significant differences between the groups, but the absolute differences were small. Housing conditions were worse among those participants who did not have a latrine. Fewer than half of them lived in a house in which all floor spaces were dry, whereas among those who did have a latrine almost three quarters lived in such a house (Table I).

\section{B. Personal Hygiene (Table II)}

Personal hygiene related to STH infections was generally better among those who had a latrine than among those who did not (Table II). On all nine self-reported indices of personal-hygiene behaviour, the percentage of participants who reported that they practiced "good" behaviour was higher in the group that had a latrine than in the group that did not have a latrine. The same was true for the three types of physical evidence of STH infection-related hygiene.

\section{Environmental Outcomes (Table III)}

As shown in Table III, a total of 106 water samples were taken: 50 from wells used by households with latrines and 56 from wells used by households without latrines. Samples taken from wells used by households without latrines were all contaminated with E. coli. However, in the village with household latrines $40 \%$ of the wells had no E. coli. Also, $91 \%$ of the wells used by non-latrine households were highly contaminated (> $240 \mathrm{cfu} / 100 \mathrm{ml}$ ) compared with only $16 \%$ of the wells used by households with latrines.

\section{Individual-Health Outcomes (Table III)}

For all five of the self-reported symptoms and illnesses, the prevalences were higher among the participants who did not have a latrine than among those who had a latrine.

\section{E. Social Outcome (Table III)}

One outcome measured in this study that reflects the social impact of STH infection is the number of days of absence from work or school attributed to bowel infection. The percentage of participants who reported having missed at least one day of work or school due to a bowel infection in the previous three months was more than six times higher among the participants who did not have a latrine than among those who had a latrine $(40.3 \%$ vs $6.2 \%)$. 
TABLE I: BACKGROUND

\begin{tabular}{|c|c|c|c|c|}
\hline & Total $(n=804)$ & Without latrine $(n=400)$ & With latrine $(n=404)$ & $p^{a}$ \\
\hline \multicolumn{5}{|l|}{ Biological characteristics } \\
\hline \multicolumn{5}{|l|}{ Sex } \\
\hline Female & $406(50.5 \%)$ & $203(50.8 \%)$ & $203(50.2 \%)$ & $0.888^{b}$ \\
\hline Male & $398(49.5 \%)$ & $197(49.3 \%)$ & $201(49.8 \%)$ & \\
\hline \multicolumn{5}{|l|}{ Age } \\
\hline Mean \pm SD & $29.9 \pm 17.0$ & $29.9 \pm 17.0$ & $28.6 \pm 16.0$ & $0.040^{c}$ \\
\hline Min-Max & $3-70$ & $3-70$ & $3-62$ & \\
\hline Children (age 3-15) & $199(24.9 \%)$ & $97(24.3 \%)$ & $103(25.5 \%)$ & $0.684^{b}$ \\
\hline Adults & $605(75.1 \%)$ & $303(75.7 \%)$ & $301(74.5 \%)$ & \\
\hline Weight (kg) & $47.1 \pm 15.6$ & $45.7 \pm 14.9$ & $48.5 \pm 16.1$ & $0.002^{c}$ \\
\hline Height $(\mathrm{cm})$ & $148.1 \pm 23.2$ & $146.4 \pm 23.7$ & $149.9 \pm 22.5$ & $0.001^{c}$ \\
\hline \multicolumn{5}{|l|}{ Social-demographic information } \\
\hline \multicolumn{5}{|l|}{ Status in family } \\
\hline Head of household & $224(27.9 \%)$ & $118(29.5 \%)$ & $106(26.2 \%)$ & $0.197^{b}$ \\
\hline Wife & $206(25.1 \%)$ & $104(26.0 \%)$ & $102(25.2 \%)$ & \\
\hline Child & $343(42.7 \%)$ & $168(42.0 \%)$ & $175(43.4 \%)$ & \\
\hline Others & $31(3.9 \%)$ & $10(2.5 \%)$ & $21(5.2 \%)$ & \\
\hline \multicolumn{5}{|l|}{ Schooling } \\
\hline No schooling & $37(4.6 \%)$ & $18(4.5 \%)$ & $19(4.7 \%)$ & $<.001^{d}$ \\
\hline Kindergarten & $45(5.6 \%)$ & $22(5.5 \%)$ & $23(5.7 \%)$ & \\
\hline Elementary & $426(53.0 \%)$ & $242(60.5 \%)$ & $184(45.5 \%)$ & \\
\hline Junior secondary & $177(22.0 \%)$ & $82(20.5 \%)$ & $95(23.6 \%)$ & \\
\hline Senior secondary & $101(12.6 \%)$ & $35(8.8 \%)$ & $66(16.3 \%)$ & \\
\hline University & $18(2.2 \%)$ & $1(0.3 \%)$ & $17(4.2 \%)$ & \\
\hline \multicolumn{5}{|l|}{ Religion } \\
\hline Islam & $793(98.6 \%)$ & $400(100 \%)$ & $393(97.3 \%)$ & $0.001^{b}$ \\
\hline Catholic & $11(1.4 \%)$ & 0 & $11(2.7 \%)$ & \\
\hline \multicolumn{5}{|l|}{ Employment $(\mathrm{n}=1019)$} \\
\hline Unemployed & $126(15.7 \%)$ & $50(12.5 \%)$ & $76(18.8 \%)$ & $<.001^{d}$ \\
\hline Unskilled employee & $346(43.0 \%)$ & $199(49.8 \%)$ & $147(36.4 \%)$ & \\
\hline Self-employed & $92(11.4 \%)$ & $32(8.0 \%)$ & $60(14.9 \%)$ & \\
\hline Farmer & $31(3.9 \%)$ & $18(4.5 \%)$ & $13(3.2 \%)$ & \\
\hline Government-employed & $6(0.8 \%)$ & 0 & $6(1.5 \%)$ & \\
\hline Students/home duties & $203(25.2 \%)$ & $101(25.3 \%)$ & $102(25.25)$ & \\
\hline \multicolumn{5}{|l|}{ Monthly income (Ruphia) } \\
\hline No income & $325(40.4 \%)$ & $147(36.8 \%)$ & $178(44.1 \%)$ & $<.001^{d}$ \\
\hline$<500 \mathrm{~K}$ & $81(10.1 \%)$ & $63(15.8 \%)$ & $18(4.4 \%)$ & \\
\hline$<1,000 \mathrm{~K}$ & $365(45.4 \%)$ & $178(44.5 \%)$ & $187(46.3 \%)$ & \\
\hline$<2,000 \mathrm{~K}$ & $30(3.7 \%)$ & $12(3.0 \%)$ & $18(4.5 \%)$ & \\
\hline $2,000 \mathrm{~K}$ or $>2,000 \mathrm{~K}$ & $3(0.4 \%)$ & 0 & $3(0.7 \%)$ & \\
\hline \multicolumn{5}{|l|}{ Housing conditions } \\
\hline \multicolumn{5}{|c|}{ Dry floors (entrance, guestroom, bedroom, kitchen) } \\
\hline No dry space & $84(10.4 \%)$ & $37(9.3 \%)$ & $47(11.6 \%)$ & $<.001^{d}$ \\
\hline 1 dry space & $122(15.2 \%)$ & $79(19.8 \%)$ & $43(10.6 \%)$ & \\
\hline 2 dry spaces & $21(2.6 \%)$ & $12(3.0 \%)$ & $9(2.3 \%)$ & \\
\hline 3 dry spaces & $56(7.0 \%)$ & $46(11.5 \%)$ & $10(2.5 \%)$ & \\
\hline All spaces dry & $521(64.8 \%)$ & $226(56.5 \%)$ & $295(73.0 \%)$ & \\
\hline \multicolumn{5}{|l|}{ Wall material } \\
\hline Full bamboo & $6(0.7 \%)$ & $6(1.5 \%)$ & 0 & $<.001^{d}$ \\
\hline Bamboo \& wood & $2(2.0 \%)$ & $2(0.5 \%)$ & 0 & \\
\hline Bamboo \& brick & 0 & 0 & 0 & \\
\hline Full wood & $64(8.0 \%)$ & $32(8.0 \%)$ & $32(7.9 \%)$ & \\
\hline Wood \& brick & $29(3.3 \%)$ & $5(1.3 \%)$ & $24(5.9 \%)$ & \\
\hline Full brick & $703(87.4 \%)$ & $355(88.8 \%)$ & $348(86.2 \%)$ & \\
\hline \multicolumn{5}{|l|}{ Lighting } \\
\hline Poor & $28(3.5 \%)$ & $28(7.0 \%)$ & 0 & $<.001^{d}$ \\
\hline Good & $682(84.8 \%)$ & $282(70.5 \%)$ & $400(99.0 \%)$ & \\
\hline Very good & $94(11.7 \%)$ & $90(22.5 \%)$ & $4(1.0 \%)$ & \\
\hline
\end{tabular}

\footnotetext{
${ }^{a}$ Tests of differences between those with and those without a household latrine.
}

${ }^{\mathrm{b}}$ Fisher's exact test. ${ }^{\mathrm{c}}$ Mann-Whitney U test. ${ }^{\mathrm{d}}$ Pearson Chi-square test. 
TABLE II: PERSONAL HyGIENE: BEHAVIOURS AND PHYSICAL EVIDENCE

Total
Self-reported behaviours $\quad \frac{\begin{array}{c}\text { Without latrine } \\ (n=804)\end{array}}{n}$

\begin{tabular}{ccc}
$\begin{array}{c}\text { Total } \\
(n=804)\end{array}$ & $\begin{array}{c}\text { Without latrine } \\
(n=400)\end{array}$ \\
\hline
\end{tabular}

$p^{a, b}$

How do you clean yourself when you pass motions in the bush? (Prevalence of "Leaves or river")

$\begin{array}{rccc}\text { Prevalence } & 20.7 \%(110 / 561) & 40.5 \%(85 / 210) & 8.8 \%(31 / 351) \\ 95 \% \mathrm{CI}^{\mathrm{c}} & 16.3 \% \text { to } 22.9 \% & 33.8 \% \text { to } 47.1 \% & 5.9 \% \text { to } 11.8 \% \\ \text { Missing data } & 243 & 190 & 53\end{array}$

or buy your water for drinking? (Prevalence of "No")

Do you always boil or buy your water for drinking? (Prevalence of "No")
Prevalence $0.7 \%(6 / 804)$

$\begin{array}{rll}\text { Prevalence } & 0.7 \%(6 / 804) & 1.3 \%(5 / 400) \\ 95 \% \mathrm{CI} & 0.2 \% \text { to } 1.3 \% & 0.2 \% \text { to } 2.3 \%\end{array}$

$0.2 \%(1 / 404)$

0.122

$0.0 \%$ to $1.5 \%$

Do you drink unboiled water from a well or pipe? (Prevalence of "Yes")

$\begin{array}{rrr}\text { Prevalence } & 12.9 \%(104 / 804) & 24.3 \%(97 / 400) \\ 95 \% \text { CI } & 10.6 \% \text { to } 15.3 \% & 20.0 \% \text { to } 28.4 \%\end{array}$

$1.7 \%(7 / 404)$

$<0.001$

$0.5 \%$ to $3.0 \%$

Do you wash or peel fruit before eating it? (Prevalence of "Not always")

$\begin{array}{rrr}\text { Prevalence } & 10.0 \%(80 / 804) & 14.3 \%(57 / 400) \\ 95 \% \mathrm{CI} & 7.9 \% \text { to } 12.0 \% & 10.8 \% \text { to } 17.9 \%\end{array}$

$5.7 \%(23 / 404)$

$<0.001$

$3.4 \%$ to $7.9 \%$

Do you wash hands before eating? (Prevalence of "Not often")

$\begin{array}{rlll}\text { Prevalence } & 8.7 \%(70 / 804) & 12.3 \%(49 / 404) & 5.2 \%(21 / 404) \\ 95 \% \mathrm{CI} & 6.8 \% \text { to } 10.7 \% & 9.0 \% \text { to } 15.5 \% & 3.0 \% \text { to } 7.4 \%\end{array}$

Do you eat with a spoon or similar utensil? (Prevalence "Not often")

$\begin{array}{rlll}\text { Prevalence } & 14.3 \%(115 / 804) & 24.3 \%(97 / 400) & 4.5 \%(18 / 404) \\ 95 \% \mathrm{CI} & 11.9 \% \text { to } 16.7 \% & 20.0 \% \text { to } 28.4 \% & 2.4 \% \text { to } 6.5 \%\end{array}$

Do you bite your fingers or nails? (Prevalence of "Often")

$\begin{array}{rlll}\text { Prevalence } & 7.0 \%(56 / 804) & 10.3 \%(41 / 400) & 3.7 \%(15 / 404) \\ 95 \% \mathrm{CI} & 5.2 \% \text { to } 8.7 \% & 7.3 \% \text { to } 13.2 \% & 1.9 \% \text { to } 5.5 \%\end{array}$

Do you routinely cut your nails? (Prevalence of "Not routine")

$\begin{array}{rrrrr}\text { Prevalence } & 38.9 \%(313 / 804) & 41.3 \%(165 / 400) & 36.6 \%(148 / 404) & 0.193 \\ 95 \% \text { CI } & 35.6 \% \text { to } 42.3 \% & 36.4 \% \text { to } 46.1 \% & 31.9 \% \text { to } 41.3 \%\end{array}$

How often do flies get into food at home? (Prevalence of "Often or sometimes")

$\begin{array}{rrrr}\text { Prevalence } & 19.4 \%(156 / 804) & 25.0 \%(100 / 400) & 13.9 \%(56 / 404) \\ 95 \% \text { CI } & 16.7 \% \text { to } 22.1 \% & 20.8 \% \text { to } 29.2 \% & 10.5 \% \text { to } 17.2 \%\end{array}$

Physical evidence of personal hygiene

Often see faeces around the house? (Prevalence of "Yes")

$\begin{array}{rllll}\text { Prevalence } & 12.2 \%(98 / 804) & 15.8 \%(63 / 400) & 8.7 \%(35 / 404) & 0.002 \\ 95 \% \text { CI } & 9.9 \% \text { to } 14.4 \% & 12.2 \% \text { to } 19.3 \% & 5.9 \% \text { to } 11.4 \%\end{array}$

Nails (Prevalence of "Not all clean")

$\begin{array}{ccccc}\text { Prevalence } & 14.5 \%(111 / 804) & 21.3 \%(85 / 400) & 6.4 \%(26 / 404) & 4 \\ 95 \% \text { CI } & 11.4 \% \text { to } 16.2 \% & 17.2 \% \text { to } 25.3 \% & 4.0 \% \text { to } 8.8 \% \\ & & & 8.001 \\ \text { "Not all clean") } & & 17.5 \%(70 / 400) & 5.2 \%(33 / 404) & <.5 \% \text { to } 10.8 \% \\ \text { Prevalence } & 12.8 \%(103 / 804) & 13.8 \% \text { to } 21.2 \% & 001\end{array}$

\footnotetext{
${ }^{\mathrm{a}}$ Tests of differences between those with and those without a household latrine.

${ }^{\mathrm{b}}$ Fisher's exact test.

${ }^{\mathrm{c}}$ Confidence interval of prevalence.
} 
TABLE III: OUTCOMES

Total

$(n=804)$

\section{Environmental outcomes}

Contamination of well water with E. coli

Wells $\quad 86 / 106(81.1 \%)$

E. coli contamination level
$59 / 106(55.7 \%)$

$20 / 106(18.9 \%)$
Without latrine

$(n=400)$
With latrine

$(n=404)$ $p^{a, b}$

$\longrightarrow$

\section{Individual-health outcomes (self-reported symptoms and illnesses)}

Over the last 3 months, have you experienced any pinworms? (Prevalence of "Yes")

$\begin{array}{rcccc}\text { Prevalence } & 12.9 \%(102 / 793) & 24.8 \%(97 / 391) & 1.2 \%(5 / 402) & 0.001 \\ 95 \% \text { CI } & 10.5 \% \text { to } 15.2 \% & 20.5 \% \text { to } 29.1 \% & 0.2 \% \text { to } 2.3 \% \\ \text { Missing data } & 11 & 9 & 2\end{array}$

Over the last 3 months, have you had a bowel infection? (Prevalence of "Yes")

$\begin{array}{rlll}\text { Prevalence } & 10.4 \%(84 / 804) & 12.8 \%(51 / 400) & 8.2 \%(33 / 404) \\ 95 \% \mathrm{CI} & 8.3 \% \text { to } 12.6 \% & 9.5 \% \text { to } 16.0 \% & 5.5 \% \text { to } 10.8 \%\end{array}$

Itching in anus today? (Prevalence of "Yes")

$\begin{array}{rccc}\text { Prevalence } & 2.7 \%(22 / 804) & 4.5 \%(181 / 400) & 1.0 \%(4 / 404) \\ 95 \% \mathrm{CI} & 1.6 \% \text { to } 3.9 \% & 2.5 \% \text { to } 6.5 \% & 0.02 \% \text { to } 1.9 \%\end{array}$

Any worms in stool today? (Prevalence of "Yes")

$\begin{array}{rlll}\text { Prevalence } & 1.4 \%(11 / 804) & 2.5 \%(10 / 400) & 0.2 \%(1 / 404) \\ 95 \% \mathrm{CI} & 0.6 \% \text { to } 2.2 \% & 1.0 \% \text { to } 4.0 \% & 0.0 \% \text { to } 0.7 \%\end{array}$

Stomach or abdominal pain today? (Prevalence of "Yes")

$\begin{array}{rlcll}\text { Prevalence } & 1.4 \%(11 / 804) & 2.8 \%(11 / 400) & 0 & <0.001 \\ 95 \% \mathrm{CI} & 0.6 \% \text { to } 2.2 \% & 1.1 \% \text { to } 4.3 \% & 0\end{array}$

\section{Social outcome (self-reported absence from school or work)}

How many days were you absent from work or school? (Prevalence of "1 day or longer")

$\begin{array}{rrrr}\text { Prevalence } & 23.1 \%(186 / 804) & 40.3 \%(161 / 400) & 6.2 \%(25 / 404)<0.001 \\ 95 \% \mathrm{CI} & 20.2 \% \text { to } 26.0 \% & 35.4 \% \text { to } 45.1 \% & 3.8 \% \text { to } 8.5 \%\end{array}$

\footnotetext{
${ }^{a}$ Tests of differences between those with and those without a household latrine.

${ }^{\mathrm{b}}$ Fisher's exact test.

${ }^{\mathrm{c}}$ Confidence interval of prevalence.
} 


\section{DisCUSSION}

This study has found associations between all of the outcomes measured and the presence or lack of a latrine. Specifically, in the village with latrines (a) there was less contamination of water, (b) symptoms of STH infection were less prevalent, and (c) bowel infection-related absence from work or school was also less prevalent.

Important aspects of personal hygiene relevant to gastroenteritis and STH infection were better amongst those in households with the BALatrine than amongst those in households without a latrine. This indicates the importance of health education and health promotion and improving the overall health literacy amongst villagers. For example, participants living in households without latrines more commonly cleaned themselves in the river or used leaves after passing a motion; they also more commonly drank water from wells or pipelines that was not boiled. They tended not to wash or peel fruit before eating it, not to wash their hands before eating, to eat without a utensil and flies more frequently got into their food at home. This is consistent with previous knowledge regarding behaviours that promote the spread of gastroenteritis and helminthiasis [6]. The clear differences in behaviour between those in households with latrines and those in households without latrines merits additional investigation.

Regarding the environmental outcomes, the present findings show, not surprisingly, that people who live with highly contaminated well water are at a high risk for gastroenteritis. This suggests that latrine development using a "total latrine village" strategy could decrease the risk of well contamination substantially.

One strength of this study is that it includes a "social" outcome: absence from work or school due to bowel infection in the past three months. As shown in Table III, such absences were much more common among those participants who did not have a household latrine. For students, absence from school is certainly important, although its costs in terms of opportunities and income foregone may be difficult to quantify. For a low-income worker, however, clearly the loss of income caused by even one day's absence from work could be quite burdensome to the household. A follow-up study would allow more precise estimates of the economic losses caused by STH infections, and of the economic benefits attributable to household latrines.

\section{CONCLUSION}

At this stage, we are not able to make causal statements and additional research is required to identify conclusively that the introduction of a latrine such as the BALatrine leads to improved health and environment. While the results of the present study strongly suggest that implementation of the BALatrine is a very beneficial intervention, more work remains to be done. Specifically, the interpretation of the present results is limited by the fact that this study was cross-sectional. To overcome that limitation, a longitudinal, randomized, controlled trial of the effects of the BALatrine is justified. By revealing cause-effect relationships, such a study could more clearly answer the question regarding whether the relatively simple BALatrine can be an effective, culturally appropriate intervention against gastroenteritis and helminthiasis, and thereby help to break the cycle of disease and poverty.

\section{ACKNOWLEDGMENT}

We are grateful to the residents of the villages for participating in this study.

\section{REFERENCES}

[1] Laporan Nasional-Riset Kesehatan Dasar (LNRKD) Indonesia, Badan Penelitian dan Pengembangan Kesehatan (Balitbangkes) Kementerian kesehatan (Kemenkese), Republik Indonesia (RI), 2010.

[2] Laporan Hasil-Riset Kesehatan Dasar (LHRKD) Indonesia, Badan Penelitian dan Pengembangan Kesehatan (Balitbangkes) Departemen Kesehatan (Depkes), Republik Indonesia (RI), 2007.

[3] Water and Sanitation Program (WSP). (2010). Social factors impacting the use of EcoSan in rural Indonesia: Learning Note. [Online]. Available: http://www.wsp.org

[4] L. Cameron and M. Shah. Scaling up rural sanitation: Findings from the impact evaluation baseline survey in Indonesia. Global Scaling-Up Rural Sanitation Project, Cater and Sanitation Program Technical Paper. [Online]. Available: http://www.wsp.org

[5] World Health Organization (WHO) and UNICEF, Meeting the MDG Drinking Water and Sanitation Target: The Urban and Rural Challenge of the Decade, Geneva, 2006.

[6] World Health Organization (WHO). Fact sheets on environmental $\begin{array}{lll}\text { sanitation. } & \text { [Online]. Available: }\end{array}$ http://www.who.int/water_sanitation_health/hygiene/emergencies/env sanfactsheets/en/index2.html

[7] Health Department of Pekalongan District, Annual Report, Health Department, Depkes, Pekalongan, 1998.

[8] Departemen Kesehatan Republik Indonesia, Pedoman pengendalian cacingan. Jakarta: Lampiran Menteri Kesehatan, Nomor: 424/ MENKES /SK/VI/2006, 2006.

[9] Buku Situasi Penyakit. (2010). Ditjen Pengendalian Penyakit dan Penyehatan Lingkungan Kemenkes RI. [Online]. Available: http://pppl.depkes.go.id/upt?id=90

[10] Central Java Health Department. (2003). Bab IV: Pencapaian program kesehatan menuju jawa tengah sehat. Profile kesehatan province jaw tengah. [Online]. Available: http://www.dinkesjatengprov.go.id/dokumen/profil/2003/bab4.htm

[11] B. Laksono, "The number of family latrines in Kedung Wuni, Pejalongan Pekalongan and its problems," Health Department Pekalongan, Pekalongan, Indonesia, 1995.

[12] S. Hendratno, "Oxyuriasis pada siswa Sekolah Dasar di Kecamatan Kandang Serang Kabupaten Pekalongan," Majalah Kedokteran Tropis Indonesia, vol. 7, pp. 2-10, 1994.

[13] P. Anggoro, "Pinworm infection among school children in Jakarta," Jurnal Kesehatan Masyarakat Indonesia, vol. 3, pp. 5-12, 2005.

[14] Central Java Health Department, Fundamental Health Research Report, 1998.

[15] Z. Fatoni and D. E. Stewart, "Sanitation in an emergency situation: a case study of the eruption of Mt Merapi, Indonesia, 2010," International Journal of Environmental Protection, vol. 2, pp. 1-5, 2012.

[16] D. Stewart and B. Laksono, "Helminth infection, human waste and appropriate technology: An Indonesian case study," Environmental Health, vol. 2, pp. 46-52, 2002.

[17] B. Laksono, D. Gray, A. Clements, R. Sadler, M. J. Park, and D. Stewart, "Appropriate technology for sanitation and hygiene: the BALatrine model," Health Education, (submitted for publication), 2014.

[18] E. Edelduok, J. Eyo, and E. Ekpe, "Soil-transmitted helminth infections in relation to the knowledge and practice of preventive measures among school children in rural communities in South-Eastern Nigeria,' Journal of Pharmacy and Biological Sciences, vol. 5, pp. 33-37, 2013.

[19] P. I. Agi, "Comparative helminth infections of man in two rural communities of the Niger Delta, Nigeria," West African Journal of Medicine, vol. 16, pp. 232-236, 1997.

[20] G. O. Adeoye, C. O. Osayemi, O. Oteniya, and S. O. Onyemekeihia, "Epidemiological studies of intestinal helminthes and malaria among 
children in Lagos, Nigeria," Pakistan Journal of Biological Sciences, vol. 10, pp. 2208-2212, 2007.

MJ Park is a graduate of Konyang University's Department of Nursing Science. After graduation she worked as a nurse in operating theatres and on an oncology ward. She later worked in community-based survey research, focusing on the implementation and evaluation of health-education programs. She received masters and doctoral degrees from the Graduate School of Medicine at the University of Tokyo, and she is now a research fellow in the School of Public Health at Griffith University.

Budi Laksono was born in Semarang in 1963, educated in Indonesia at Semarang (MD) and in Brisbane, Australia (MHSc) and is a graduate of the Doctoral Program at Diponegoro University in Semarang, Indonesia. He worked as the head of Public Health Services in Pekalongan-Central Java Province where he studied the waterborne diseases that cause major sickness and death in Indonesia to help solve this problem. The amphibious latrine and total family latrine in villages ("katajaga") was developed and applied to solve the sanitation problem among families. These programs have been applied in a number of villages and now some cities have also adopted these programs to scale up for all family in a city. Currently, the impact of the 'BALatrine' program is the focus for study in joint research between Undip and Griffith University with UBS Optimus foundation donor. Dr. Laksono also provides a pilot service for HIV/AIDS and drug abuse victims in Indonesia in Harm Reduction services. He was given an award as the best medical doctor in Central Java 1997, also an award for humanitarian services by the City of Semarang (2009-2010), an MDGs award (2012), and a Changemaker award (Rotary Club, 2012).

Ross Sadler has over 30 years experience in the environmental field and has worked in Australia, Canada and the UK. He is a graduate of The University of Queensland and has been involved with a number of major environmental projects in this state, including emergency response to chemical incidents, harmful algal blooms, and cleanup of contaminated sites. Ross has undertaken research into a variety of environmental areas including the accumulation of pesticide residues in foods, sugar mill waste treatment, tracking of faecal pollution, mobility and bioavailability of pesticides in environmental matrices, and harmful algal blooms. In recent years, he has also undertaken research into the effects of climate change on pollutant behaviour, with particular reference to the Asia-Pacific region. He has chaired a number of Standards Australia committees and currently leads the NATA Environmental Technical Group as well as being program director of environmental chemistry with the Federation of Asian Chemical Societies.

Archie Clements is a professor in the School of Population Health of the University of Queensland. He is an infectious disease epidemiologist with a research focus on improving the efficiency and effectiveness of public health interventions. Specific diseases on which he works include parasitic diseases, such as schistosomiasis, soil-transmitted helminths and echinococcosis; mosquito-borne diseases, such as malaria and dengue; and emerging healthcare-acquired infections, such as Clostridium difficile. He leads a team that uses contemporary epidemiological tools, including spatial epidemiology, mathematical modelling and molecular epidemiology to investigate globally important infectious diseases.

Donald E. Stewart was educated in the United Kingdom at Durham (BA(Hons)), Oxford (PGCE), and Leicester (MA), also at Otago (NZ) (PhD), and UNSW Australia (MPH). Currently he is a professor of health promotion at the School of Public Health, Griffith University, and Vice President of the South West Pacific Region of the IUHPE, he has over 35 years of international experience in the fields of public health, education, and community development. He is the recipient of grants from the UBS Optimus Foundation investigating Helminthiasis. His work in China and Vietnam has focused on intersectoral health promotion using the health-promoting school approach to prevent infection by soil-transmitted helminths. His current project in Indonesia investigates the role of local latrine construction in reducing helminth infection. 